\title{
Substantial factors for decision-making in syllabification in Russian
}

Galina Kedrova, Valentina Kolybasova

Lomonosov Moscow State University, Russian Federation

https://oi.org/10.36505/ExLing-2017/08/0014/000316

\begin{abstract}
Present study investigates significant factors essential for decision-making in syllabification in Russian. Words representing various types of actual phonotactic constraints and regular phonetic processes in Russian speech has been elected as experimental dataset. Results of syllabification experiments reveal preferred individual syllabification strategies, among the most stable should be mentioned tendency for predominance of V-coda syllables over C-codas. Other influential principles of syllabification are: 1) predomination of consonantal clusters in syllable's onset, 2) tendency to avoid syllables consisting of a single vowel, 3) a kind of a glottal stop at the beginning of vowel's articulation at the word's onset. Orthographic and phonetic transparency/opacity of a word has also been stated one of the crucial factors for syllables boundaries in consonantal clusters.
\end{abstract}

Key words: Syllabification; Russian language, grapheme/phoneme misalignments

\section{Introduction}

The role of syllable as core element in speech production has been universally acknowledged in the phonetic science. However, results of multiple syllabification experiments using either straightforward or very sophisticated experimental procedures and techniques are rather ambiguous. Therefore, despite all efforts to explain mechanism(s) and principles of syllabification in various languages productive and/or perceptive role of a syllable as fundamental linguistic notion is still unclear and generally admitted to raise intricate problems (Krakow 1999). One of the most challenging is the problem of verification of syllabification principles in various languages (Goslin 2001).

Whereas at the very beginning of experimental research activity in the field most theories of syllable and syllabification procedures were based mainly on the English language data, in the past two decades emerged more experimental evidence for various world languages. Most of them support idea of syllable as language-dependent special linguistic segmentation unit as well as minimal motor planning component of speech articulation. Russian language data on syllables typology and syllabification behaviour in Russian speech, which dates from early 1990s, is abundant and diversified (Bondarko 2000). However, main stumbling block of all concepts of the Russian syllabification strategies deals

ExLing 2017: Proceedings of 8th Tutorial and Research Workshop on Experimental Linguistics, 19-22 June, Heraklion, Crete, Greece 
with so-called 'syllabification boundaries problem'. While every Russian speaker unambiguously identifies number of syllables in a Russian word (with very few and very well known exceptions), she/he regularly disaccords on indicating syllables boundary within a word. Thus, following numerous experimental data Zlatoustova put forward a proposal on fundamental impossibility to match syllable boundaries in the Russian.

To distinguish languages of similar type from syllablecounting languages, Kodzasov proposed a special term for the languages with intrinsic 'floating' syllable boundaries: a 'wave' language (unlike 'quantum' language). While most experimental data evidenced in favour of prevailing type of the open syllable (CV) model in Russian, many linguists yet consider idea of universality of the $\mathrm{CV}$-model for the Russian language still a challenging one. Therefore, the main purpose of the present study was to discern potential influence of phonetic processes in consonant and vocalic clusters in Russian speech on syllabification strategies of speakers.

\section{Experimental data and procedures}

Our research differs from previous ones in approach to experimental stimuli phonetic parameters. Experimental stimuli dataset composition was composed of Russian words representing various types of phonotactic constraints and phonetic transformations occurring in Russian speech (vowel reduction, sonorisation / devocalization, regular assimilation patterns occurring in consonantal clusters, dissimilation, hiatus, consonantal dropouts and schwa insertion). The dataset was balanced according to degree of orthographic and phonetic transparency/opacity of a word (mismatch between spelling and pronunciation) while it has been already demonstrated that factor of transparent $v s$ opaque orthography proved its validity for experimental subjects' behaviours in French (Chetail 2012).

The experimental set of word items comprised 653 words with 1.893 potential syllables equal to the number of vowel characters (1.903 syllables considering syllables with verified schwa insertions). The dataset was sequentially reorganized according to the principle of accrescent pronunciation and reading complexity. All word items were split into 3 word sets, each presented to experimental subject in consequent sub-series during one experimental session. Each series word set also differed on proportion of size and constitution of consonant clusters (Table $1)$. 
Table 1: Experimental stimuli data parameters. Legend for data in Table 1: $\mathrm{N}(\mathrm{w})$ - number of words; $\mathrm{N}(\mathrm{s})$ - number of syllables; $\mathrm{N} 2$ - 2-component consonantal clusters; N3 - 3-component consonantal clusters; N4 - 4component consonantal clusters; N5 - 5-component consonantal clusters; $\mathrm{N}(\mathrm{a})$ - phonetic transformations in consonant clusters.

\begin{tabular}{|c|c|c|c|c|c|c|c|}
\hline \hline Series & $\mathrm{N}(\mathrm{w})$ & $\mathrm{N}(\mathrm{s})$ & $\mathrm{N} 2$ & $\mathrm{~N} 3$ & $\mathrm{~N} 4$ & $\mathrm{~N} 5$ & $\mathrm{~N}(\mathrm{a})$ \\
\hline 1 & 218 & 216 & 626 & 15 & 0 & 0 & 30 \\
\hline 2 & 219 & 650 & 708 & 27 & 8 & 1 & 57 \\
\hline 3 & 70 & 350 & 569 & 53 & 12 & 0 & 107 \\
\hline \hline
\end{tabular}

Subjects included 5 adult native speakers of Russian (4 males and 1 female) of ages between 31 and 65 with various professional and educational experiences. Three of the experimental subjects were professional linguists ( 2 of them phoneticians); one subject was mathematician and one a physicist. A list of words split into three quasi-equal sub-lists (series) was presented to experimental subjects on a computer screen to be syllabified orally. After completing the main experimental task on syllabification subjects were asked to read experimental stimuli from the screen as naturally as possible and at own pace. All the speaking activities has been recorded and later transcribed manually by the professional phoneticians.

\section{Results}

None of the experimental subjects posed any questions concerning experimental instruction, while the very idea of 'syllable' as word constituent has been generally introduced in Russian elementary school education. However, main results of segmentation of test words into syllables by experimental subjects revealed considerable discrepancies in individual syllabification strategies and syllables' inventory for every speaker. Results of segmentation of experimental words into syllables according to syllable codas (V/C) for every participant in all experimental sessions are presented in Figure 1.

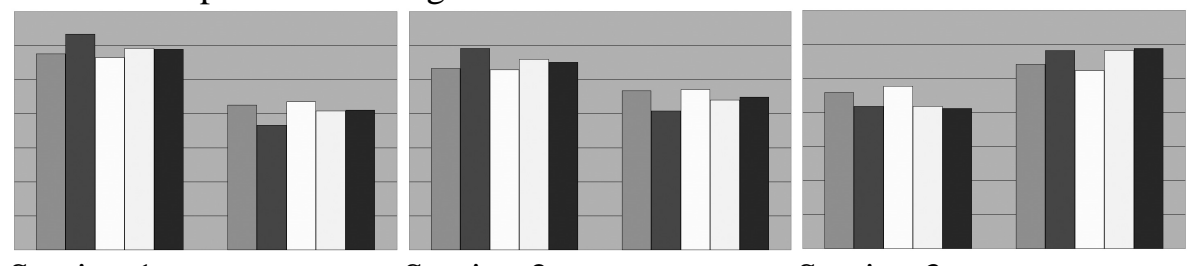

Session 1

Session 2

Session 3

Figure 1. V-codas (left cluster) and C-codas syllables (right cluster) for every subject in each session. 


\section{Conclusions}

Analysis of the results of recorded and transcribed experimental subjects syllabification behaviours reveals personal preferences for V-coda syllables vs C-coda syllable. Other influential principles of syllabification are: predomination of consonantal clusters in syllable's onset $v s$ syllable's codas; tendency to avoid syllables consisting of a single vowel or syllables with vowel onset; glottal stop at the beginning of vowel's articulation at the word's onset. These findings corroborate previous reports on maximum onset principle as a universal one for structurally different languages. Hypothesis of pre-planning strategies underlying execution of oral syllabification task depending on language writing system (Chetail 2006) was also strongly supported by our results. Russian words without or with minimum orthographic mismatch tend to be segmented in a more uniform manner, while dataset with less opaque spelling caused considerable inconsistency within a subject's individual syllabification behaviours alongside with more homogeneous syllabification decisions in more complicated cases for all subjects.

\section{References}

Bondarko, K.B., Skrelin, L.V., Shalonova, P.A. 2000. Statisticheskie kharakteristiki otkrytyh slogov. VOX. Budapest, 2000.

Chetail, F., Content, A. 2012. Segmentation of Written Words in French. Language and Speech 56, 125-144.

Chetail, F., Scaltritti, M., Conten, A. 2006. Effect of the consonant-vowel structure of written words in Italian. Quarterly Journal of Experimental Psychology 67 (5), 833-42.

Goslin, J., Frauenfelder, U.H. 2001. A comparison of theoretical and human syllabification. Language and Speech 44, 409-436.

Krakow, R.A. 1999. Physiological organization of syllables: a review. Journal of Phonetics, 27, 23-54. 